\title{
O ensino contábil na perspectiva da aprendizagem baseada em problemas
}

\author{
Accounting teaching in the problem-based learning perspective
}

La educación contable en la perspectiva del aprendizaje basado em problemas

\section{Francisco Felipe da Silva}

Mestre em Ciências Contábeis pelo Programa de Pós-Graduação em

Ciências Contábeis da Universidade Federal do Rio Grande do Norte - UFRN

Professor do Curso de Ciências Contábeis da Faculdade Diocesana de Mossoró

Endereço: Rua Luiz Torquato da Silva, 20, Costa e Silva

CEP: 59.625-647 - Mossoró/RN - Brasil

E-mail: ffelipes@outlook.com

Telefone: (84) 99963-7913

\section{Yuri Gomes Paiva Azevedo}

Doutorando em Controladoria e Contabilidade pela Faculdade de Economia, Administração e Contabilidade de Ribeirão Preto da Universidade de São Paulo (FEA-RP/USP)

Endereço: Av. Bandeirantes, 39000 - Monte Alegre

CEP: 14049-900 - Ribeirão Preto/SP - Brasil

E-mail: yuri_azevedo@live.com

Telefone: (84) 99113-2772

\section{Aneide Oliveira Araújo}

Doutora em Ciências Contábeis pela Universidade de São Paulo

Professora do Curso de Ciências Contábeis e do Programa de

Pós-Graduação em Ciências Contábeis da Universidade Federal do Rio Grande do Norte

Endereço: Av. Salgado Filho, S/N - Centro de Ciências Sociais Aplicadas, Lagoa Nova

CEP: 59078-970 - Natal/RN - Brasil

E-mail: aneide.ufrn@gmail.com

Telefone: (84) 99974-6137

Artigo recebido em 25/02/2017. Revisado por pares em 07/05/2018. Reformulado em 30/06/2018. Recomendado para publicação em 15/10/2018 por Carlos Eduardo Facin Lavarda (Editor-Chefe). Publicado em 19/12/2018. 


\title{
Resumo
}

Este estudo objetiva analisar a percepção dos mestrandos em Ciências Contábeis da Universidade Federal do Rio Grande do Norte sobre a aplicabilidade, as competências desenvolvidas e a postura docente no Problem-Based Learning (PBL) aplicado ao ensino de Contabilidade. É uma pesquisa qualitativa, descritiva, na forma de estudo de caso, cujos dados primários foram obtidos por meio de grupo focal, após a aplicação do estudo do caso "Qual é o lucro? Quer que dê quanto?", adaptado por Benjamim Júnior (2011) para o PBL. A análise de conteúdo deu-se através da codificação aberta e axial, utilizando o Software ATLAS.ti 7®. Os resultados evidenciam que o método pode ser aplicável a diversas disciplinas do curso de Contabilidade, possibilitando a aquisição de conhecimentos interdisciplinares e da prática de mercado. O problema proposto permitiu desenvolver conhecimentos em Contabilidade Gerencial, Contabilidade Societária e Responsabilidade Social Corporativa, habilidades relacionadas com solução de problemas, análise crítica, estudo independente, trabalho autorregulado e comunicação, e atitudes de cooperação.

Palavras-Chave: Problem-based learning; Aprendizagem; Contabilidade

\begin{abstract}
This study aims to analyze the perception of Master's students in Accounting Sciences of the Federal University of Rio Grande do Norte about the applicability, skills developed and teaching position in Problem-Based Learning (PBL) applied to accounting education. It is a qualitative, descriptive research, in the form of a case study, whose primary data were obtained through a focal group, after the application of the case study "What is the profit? "How much do you want to give?" adapted by Benjamim Junior (2011) for the PBL. Content analysis took place through open and axial coding using ATLAS.ti 7® Software. The results show that the method can be applied to several disciplines of the course of Accounting, enabling the acquisition of interdisciplinary knowledge and market practice. The proposed problem allowed to develop knowledge in Management Accounting, Corporate Accounting and Corporate Social Responsibility, skills related to problem solving, critical analysis, independent study, selfregulated work and communication, and cooperative attitudes.
\end{abstract}

Keywords: Problem-based learning; Learning; Accounting

\section{Resumen}

Este estudio tiene como objetivo analizar la percepción de los estudiantes de maestría de Ciencias Contables de la Universidad Federal de Rio Grande do Norte sobre sobre la aplicabilidad, las competencias desarrolladas y la postura docente em el Problem-Based Learning (PBL) aplicado a la enseñanza de la contabilidad. Se trata de una investigación cualitativa, descriptiva, en forma de un estudio de caso, cuyos datos primarios se obtuvieron a través de un grupo focal, luego de la aplicación del estudio de caso "¿Cuál es el beneficio? ¿Cuánto quiere usted?" adaptado por Benjamin Júnior (2011) para el PBL. El análisis de contenido se realizó mediante codificación abierta y axial utilizando el software ATLAS.ti 7®. Los resultados muestran que el método puede aplicarse a varias disciplinas del curso de Contabilidad, permitiendo la adquisición de conocimientos interdisciplinarios y prácticas de mercado. El problema propuesto permitió desarrollar conocimientos en Contabilidad Gerencial, Contabilidad Corporativa y Responsabilidad Social Corporativa, habilidades relacionadas con la resolución de problemas, análisis crítico, estudio independiente, trabajo auto-regulado y comunicación, y actitudes cooperativas.

Palabras clave: Aprendizaje basado en problemas; Aprendizaje; Contabilidad 


\section{Introdução}

As transformações na sociedade e as mudanças corporativas demandam do egresso do curso de Ciências Contábeis um novo perfil compatível com o contexto de mercado. Esse perfil exige do profissional da Contabilidade, conhecimentos que vão além do técnico e científico, como, por exemplo, desenvolvimento de novas competências, habilidades de pensamento crítico-reflexivo, trabalho em equipe e solução de problemas.

Frente a esta realidade, o ensino da Ciência Contábil, sobretudo nas últimas décadas, tem despertado para a discussão sobre mudanças de paradigmas metodológicos, com fundamentação no ensino centrado na aprendizagem participativa, em que o aluno torna-se o sujeito promotor do seu conhecimento a partir de metodologias ativas de aprendizagem.

$\mathrm{O}$ que se propõe nesse debate é a migração de um paradigma conducista ou behaviorista, em que o ensino é concebido como um processo programado e rígido que permite proporcionar conteúdos e informações aos alunos por meio de técnicas instrucionais sistemáticas (MARTÍNEZ-OTERO, 2012), para uma um paradigma metodológico que promova a aprendizagem construtivista, em que o aluno seja o principal responsável por sua aprendizagem (BLANCO-ENCOMIENDA; LATORRE-MEDINA, 2008; HARRIS, 2008).

Dessa forma, no contexto das abordagens contemporâneas de aprendizagem, o ProblemBased Learning (PBL) é visto como uma abordagem educativa que utiliza complexos problemas do mundo real como fatores motivacionais para seu ponto de partida (SPRAAKMAN; JACKLING, 2014) e, nessa perspectiva, destaca-se por sua capacidade de explorar no aluno a aptidão de aprender a aprender, e o desenvolvimento de competências, nas dimensões do conhecimento, habilidades e atitudes (MARTINS; ESPEJO; FREZATTI, 2015).

Quanto à sua aplicação no ensino de Contabilidade, Frezatti e Silva (2014) afirmam que o PBL aproxima o discente da prática empresarial por meio da inserção e da intervenção na realidade, preparando-os melhor para atender às demandas do mercado de trabalho, corroborando, assim, com a perspectiva de Stanley e Marsden (2012), que apontam o PBL como um veículo ideal para incorporar o contexto da vida real contábil à sala de aula.

No entanto, apesar da importância do método aproximar os conhecimentos teóricos da prática empresarial, Stanley e Marsden (2012) e Martins e Espejo (2015) afirmam que o uso do PBL no ensino de Contabilidade ainda é incipiente, apesar das pesquisas realizadas no contexto internacional (DUCH, 2001; DUCH; GROH; ALLEN, 2001; DEELMAN; HMELO-SILVER, 2004; HANSEN, 2006; SAVERY, 2006; HOEBERIGS, 2009; FORTIN; LEGAULT, 2010; SOCKALINGAN, 2010; MANAF; ISHAK; HUSSIN, 2011; SOCKALINGAN; SCHMIDT, 2011) e no cenário nacional (SOARES, 2008; ARAÚJO; ARANTES, 2009; MIRANDA, 2010; RIBEIRO, 2010; BENJAMIM JÚNIOR, 2011; FREZATTI; SILVA, 2014; MARTINS; ESPEJO; FREZATTI, 2015; FREZATTI et al. 2016) já evidenciarem a efetividade do método PBL no desenvolvimento de competências em diversas áreas.

Considerando a importância do PBL como metodologia ativa de aprendizagem, em contraponto à visão conservadora de aulas tradicionais restritas à cópia e à memorização no ensino superior (ANDREOLI; BEHRENS; TORRES, 2012), o problema orientador desta pesquisa é: qual a percepção dos mestrandos em Ciências Contábeis da Universidade Federal do Rio Grande do Norte (UFRN), sobre a aplicabilidade, as competências desenvolvidas e a postura docente no método Problem-Based Learning (PBL) aplicado ao ensino de Contabilidade?

Nesse contexto, objetivo do presente estudo é analisar a percepção dos mestrandos do Programa de Pós-Graduação em Ciências Contábeis da Universidade Federal do Rio Grande do Norte (UFRN), sobre a aplicabilidade, as competências desenvolvidas e a postura docente no método Problem-Based Learning (PBL) aplicado ao ensino de Contabilidade.

A relevância deste estudo centra-se no debate sobre promoção de um ambiente de 
aprendizagem da Contabilidade focado em problemas relacionados à prática profissional que resultem em um melhor desempenho da aprendizagem por englobar o ensino, a pesquisa e a prática, de forma que o compartilhamento de experiências entre alunos e professores direcione a construção autônoma do conhecimento e o desenvolvimento de habilidades e atitudes (DECKER; BOUHUIJS, 2009).

O estudo justifica-se, também, pela contribuição sugerida por Frezatti e Martins (2016), que evidenciam a demanda por estudos que investiguem os benefícios e competências desenvolvidas pelas abordagens que compreendem o PBL no ensino da Contabilidade, assim como a integração da pesquisa, da teoria e do mercado de trabalho do profissional contábil.

As contribuições desta pesquisa ancoram-se na escolha do público alvo, docentes ou futuros docentes da área contábil, especialmente, por serem indivíduos que estão diretamente envolvidos na formação dos futuros profissionais contábeis. Além disso, a presente pesquisa contribui com a disseminação do PBL nos cursos de Ciências Contábeis na medida em que encoraja os docentes em formação à adoção do método em sala de aula, a partir de suas percepções da experiência com o PBL no mestrado.

Este estudo diferencia-se de outras pesquisas realizadas no âmbito nacional, tendo em vista que a unidade de análise compreende estudantes de Pós-Graduação, corroborando, assim, com a perspectiva de Dockter (2012), que descreve que ao longo das últimas décadas, a implementação do PBL vem sendo analisada em programas de Pós-Graduação, onde os alunos já adquiriram uma compreensão fundamental dos conceitos e princípios da Contabilidade, além de estarem em processo de qualificação para a docência.

$\mathrm{O}$ estudo encontra-se estruturado em cinco seções. A primeira contextualiza a importância do PBL como uma proposta de aprendizagem para discentes do curso de Ciências Contábeis, além do objetivo da pesquisa. A segunda seção apresenta o referencial teórico acerca do construtivismo e do PBL, bem como os estudos recentes publicados na área. A terceira seção demonstra os procedimentos metodológicos utilizados na pesquisa para o alcance do objetivo proposto e na quarta, tem-se a análise dos resultados.Em seguida, apresentam-se as considerações finais e as referências que serviram como base para a realização do estudo.

\section{Referencial Teórico}

\subsection{O Construtivismo}

De acordo com Savery e Duffy (1995) o construtivismo - cujos principais pensadores foram Piaget, Vygotsky, Dewey e Freire - é uma visão filosófica sobre a forma de entender e aprender algo, que se apoia na concepção de uma educação problematizadora, por meio da qual se fomenta a avaliação e ação reflexiva da realidade na busca por soluções baseando-se em três pressupostos primários (CÓRIA-SABINI, 2003; PINHO et al., 2010).

O primeiro pressuposto defende que a aprendizagem ocorre a partir das interações com o meio, ou seja, não se pode falar sobre o que é aprendido separadamente de como se aprende. O segundo pressuposto diz que o conflito cognitivo ou a perplexidade é o estimulo para a aprendizagem, determina a organização e a natureza do que é aprendido e, dessa forma, buscase um ambiente de aprendizagem com um estimulo ou uma meta. Já o terceiro pressuposto apresenta o conhecimento como evolução da interação social e da avaliação da viabilidade de entendimentos individuais, neste caso o ambiente social é crítico, os trabalhos em equipes são importantes para testar a própria compreensão e examinar a compreensão dos outros como um mecanismo para enriquecer, misturando e expandindo a compreensão das questões ou fenômenos particulares (SAVERY; DUFFY, 1995).

Sob a perspectiva do construtivismo, o conhecimento é um processo de criação e não de repetição (PIAGET, 1973), de modo que saber ensinar não consiste em transferir conhecimento, mas criar as possibilidades para a sua própria produção ou a sua construção (FREIRE, 1996). 
Dessa forma, observa-se que a Teoria Construtivista se contrapõe aos métodos tradicionais de ensino, em que o professor é o centro do processo utilizando-se de aulas expositivas na maior parte, e considera o aluno como sujeito ativo do processo de aprendizagem e como o responsável por conquistar as estruturas de conhecimento e desenvolvimento moral e intelectual (LA TAILLE, 2005).

Neste cenário, os alunos são membros de equipes colaborativas que interagem entre si e com o professor, de forma a desenvolver a aprendizagem autônoma. O papel do professor é fornecer aos alunos orientações e tarefas autênticas que representem situações do mundo real, tornando-os aptos para as exigências profissionais impostas pela sociedade, tais como: capacidade de aplicar o conhecimento adquirido; habilidade de solucionar problemas, habilidades de comunicação, habilidade de trabalhar em equipe e que sejam eternos aprendizes (SOCKALINGAM, 2010).

Ressalta-se que, apesar das metodologias ativas de aprendizagem apresentarem diversas vantagens, sua disseminação esbarra em dificuldades, sobretudo culturais, para expandi-las no ensino brasileiro (ARAÚJO; ARANTES, 2009).

\subsection{Aprendizagem Baseada em Problemas no Ensino de Contabilidade}

O Problem-Based Learning (PBL), como programa de aprendizagem, surgiu no Canadá, em meados da década de 1960, na McMaster University, e, em pouco tempo, difundiu-se em várias universidades do mundo, principalmente nos cursos de Medicina, e chegou ao Brasil na década de 1990, visando integrar o ensino à prática profissional (MARTINS; ESPEJO; FREZATTI, 2015).

Também conhecido como Aprendizagem Baseada em Problemas (ABP), o PBL é considerado uma abordagem de ensino construtivista de acordo com Savery e Duffy (1995), Hmelo-Silver (2004), Schmidt et al. (2009) e Sockalingam (2010). Na visão de Safery e Duffy (1995), o PBL é considerado referência dentre as metodologias de aprendizagem construtivistas, por permitir o desenvolvimento dos princípios educacionais do construtivismo.

Para os autores, trata-se de uma metodologia mais eficiente que as metodologias tradicionais de ensino na promoção de competências profissionais, sendo a aprendizagem autônoma um importante componente desenvolvido pelo PBL, por integrar três elementos principais: o aluno - que assume o centro do processo como principal responsável por sua aprendizagem; o professor, denominado tutor - que orienta e estimula o processo de aprendizagem; e o problema - que, não estruturado e sem uma única solução correta, reflete uma situação profissional próxima da realidade nas diversas áreas do conhecimento e é apresentado como o ponto de partida pelo professor ao aluno.

De acordo com Wood (2003), no processo do PBL os alunos organizam-se em equipes de trabalho e definem entre eles os papéis de líder, secretário-relator e membros, e de forma colaborativa investigam e resolvem problemas reais e complexos (HMELO-SILVER, 2004).

Para resolver o problema, a equipe deve seguir um roteiro de sete etapas: (i) identificar e esclarecer os conceitos desconhecidos ou confusos; (ii) definir o(s) problema(s) a ser(em) resolvido(s); (iii) em sessão de brainstorming, discutir o problema e buscar as possíveis explicações com base em conhecimentos de mundo que possuem; (iv) realizar um balanço das informações detalhando as explicações propostas; (v) formular os objetivos da aprendizagem; (vi) coletar informações através de pesquisa e estudo individualizado; e (vii) compartilhar com o grupo os conhecimentos adquiridos (WOOD, 2003).

Dessa forma, o PBL propõe a ruptura do paradigma tradicional vertical, em que o professor (ativo) é o detentor do conhecimento e o aluno (passivo) é o receptor e armazenador do conteúdo transmitido pelo professor, perfil que visto por Freire (1987) como "educação bancária", é também amplamente criticado pelos pensadores do construtivismo, como Piaget, Dewey e Vygotsky. 
O método PBL está fundamentado nos princípios da aprendizagem, como, motivação epistêmica, interação com a vida real, metacognição, construção do conhecimento e interação social (RIBEIRO, 2010). E, assim, destaca-se vantajosamente, como metodologia ativa de aprendizagem, porque permite que o aluno participe ativamente e seja aprendiz independente, ou seja, que ele desenvolva um pensamento reflexivo a partir do trabalho de pesquisa e investigação científica e da cooperação com os membros de um grupo para efetivamente resolverem uma situação problemática baseada na realidade profissional, aproximando-os do meio onde estão inseridos (HANSEN, 2006; SOARES, 2008).

Para Hmelo-Silver (2004) as vantagens da aprendizagem baseada em problemas são as seguintes: (i) construir uma base de conhecimentos ampla e flexível; (ii) desenvolver habilidades eficazes de resolução de problemas; (iii) desenvolver habilidades de aprendizagem auto-dirigida ao longo da vida; (iv) tornar-se colaboradores eficazes; e (v) tornar-se intrinsecamente motivado para aprender.

Soares (2008) destaca que os atributos que o PBL traz para a vida do profissional contábil são também algumas das competências e habilidades que a Resolução CNE/CES n ${ }^{\circ}$ 10/2004 define como características necessárias para os egressos do Curso de Graduação em Ciências Contábeis. A autora defende, também, que o PBL atende às necessidades dos professores no que se refere à aquisição de conhecimentos relativos à efetividade dos métodos educacionais.

Da mesma forma, Martins e Espejo (2015) corroboram afirmando que o método, por promover a integração entre a teoria e a prática, incentivar a pesquisa e realizar a inter, a trans e a multidisciplinaridade, atende às exigências propostas pelas diretrizes curriculares do curso de Ciências Contábeis requeridas pela referida Resolução. Porém, é importante destacar que para que as ferramentas pedagógicas de ensino construtivista contribuam para a aprendizagem, as condições determinantes devem ser satisfatórias.

Enquanto Breton (1999) relacionam conhecimento duradouro e melhores resultados obtidos nas avaliações como vantagens do PBL, Johnstone e Biggs (1998) sugerem que o PBL deve ser implementado somente nos anos terminais dos cursos, onde será possível uma integração mais clara e eficaz dos conhecimentos obtidos nas disciplinas iniciais, e recomendam ainda que os professores que utilizam o PBL em sala de aula devem possuir conhecimentos técnicos especializados na área do assunto. Dessa forma, garante-se que os alunos não desenvolvem estruturas de conhecimento organizadas de forma inadequada (FORTIN; LEGAULT, 2010).

No tocante às dificuldades de implementação do PBL, Sockalingam, Martins e Frezatti (2014) relatam que estas se relacionam com a cultura e a postura adotada pelo professor e pelos alunos, tendo em vista que eles precisam ser preparados para entender o método, bem como a importância da sua adoção. Pinheiro, Sarrico e Santiago (2011) apresentam o novo papel do docente como um dos desafios na metodologia PBL, uma vez que o professor deve agir como facilitador, planejar atividades, dialogar, orientar e guiar o aluno para que no espaço temporal previsto ele consiga desenvolver as competências que, ele próprio e o docente, perceberam como objetivos daquela aprendizagem.

De acordo com Wood (2003), há resistência por parte dos professores que não podem exercer diretamente o seu poder e seu papel de detentores do conhecimento, pois gostam de transmitir seu próprio conhecimento e compreensão, e no PBL ficam mais restritos no papel de tutores, corroborando, assim, com Escrivão e Ribeiro (2008), que descrevem que o método parece não ser um modelo instrucional interessante para todos os docentes, tendo em vista que aqueles que se consideram eficazes nos modelos tradicionais de ensino, podem não conseguir perceber a necessidade de mudanças didáticas em suas aulas.Outro desafio está no processo avaliativo em PBL, que envolve a avaliação de conhecimentos, habilidades e atitudes, e, para tanto, precisa utilizar-se de uma combinação de instrumentos diversos, inclusive autoavaliação 
e avaliação pelos pares. Martins e Espejo (2015) relatam que essa nova configuração acarreta maior responsabilidade para julgar se os objetivos da aprendizagem foram alcançados e fornecer feedback.

Ribeiro (2010), Araújo e Arantes (2009) e Oliveira (2015) relatam ainda limitações da aplicação do PBL em ciências contábeis em função dos Projetos Políticos Pedagógicos dos curso de ciências contábeis que, em sua maioria, não contemplam a inserção de metodologias ativas, como o PBL. Desse modo, os casos de aplicação do PBL terminam por serem realizados isoladamente pelos docentes em suas respectivas disciplinas.

De forma complementar, Wood (2003) e Siqueira et al. (2009) relatam outras limitações, como uma maior demanda por recursos humanos e investimentos na estrutura da instituição no sentido de adaptar os espaços destinados ao trabalho dos grupos, pois os estudantes necessitam de acesso aos recursos computacionais simultaneamente; e trabalhar a insegurança dos alunos quanto ao estudo autodirigido e autônomo.

\subsection{Estudos Recentes}

Nesta seção são apresentados os estudos recentes realizados sobre PBL no ensino de Contabilidade, tanto no cenário nacional, como no contexto internacional. Como critério de seleção dos trabalhos, foram pesquisados nas plataformas Periódicos CAPES, Spell, Scielo Brasil e Google Scholar, os termos "Aprendizagem Baseada em Problemas", "Ensino de Contabilidade", "PBL no Curso de Ciências Conábeis", "Problem-Based Learning in Accounting" e "Problem-Based Learning in Accountancy".

Dentro das perspectivas do método PBL, Frezatti e Silva (2014) objetivaram discutir as estratégias para manter o interesse dos estudantes em uma disciplina da área de negócios, face à prática versus incerteza, sendo os impactos do sistema de informações gerenciais sobre o gerenciamento das organizações o tema norteador do problema.

Os principais resultados evidenciam dez componentes-chave para o sucesso da aplicação do método, sendo eles: leilão de problemas; critério de definição do líder; processo de alocação de participantes; expansão e redução no tratamento do problema; escolha da empresa pela acessibilidade aos dados; clareza das normas de formatação e estrutura do projeto e relatório final; formas de acesso e estímulo à literatura; aulas expositivas para direcionamento e reforço das atividades; check-list das atividades das sessões tutoriais; e feedback das socializações, autoavaliação do processo e de aprendizagem.

Os autores consideram ainda que, embora os acadêmicos se motivem com a prática, não está claro o que ela representa para um grupo que, muitas vezes, é extremamente heterogêneo. Diante disso, considera-se que quanto maior for a possibilidade de haver grupos que tenham alguma semelhança em termos de experiência e conhecimentos, maior a chance de sucesso.

Objetivando relatar a operacionalização do método PBL em uma disciplina Contabilidade Gerencial no curso de Ciências Contábeis de uma Instituição de Ensino Superior brasileira, Martins, Espejo e Frezatti (2015) evidenciam que a integração entre os estudantes e as empresas, a partir da utilização dos problemas práticos e reais trazidos pelos alunos do ambiente de trabalho, proporciona ganhos como: o discente amplia o potencial de resolução de problemas de ordem prática e profissional; e a empresa é beneficiada, tendo em vista que poderá receber, futuramente, profissionais qualificados, aptos à pesquisa e à proposição de solução de problemas.

Dentre as principais competências desenvolvidas, os autores evidenciam que o trabalho em grupo e a comunicação foram as principais habilidades desenvolvidas, enquanto que o estudo independente, o trabalho autodirigido, a integração com a empresa e a análise crítica foram elencados em menor frequência pelos participantes do estudo. Em relação aos aspectos negativos, foram citados a falta de tempo para realizar os estudos independentes, a falta de planejamento do grupo para realizar o trabalho autorregulado, a dificuldade de apresentar uma 
solução a um problema aberto e, principalmente, a dificuldade dos discentes em trabalhar em grupo.

Considerando que a diferença entre a avaliação do PBL e o método tradicional de ensino, em que a avaliação pode acontecer por meio de um único instrumento ao final do semestre, o estudo de Frezatti et al. (2016) teve como objetivo atribuir significado ao conceito final obtido pelo aluno em disciplina ministrada sob a ótica do PBL, considerando a complexidade da perspectiva sinérgica dos conhecimentos, habilidades e atitudes (CHA) desenvolvidos pelo método.

Ao avaliar os processos cognitivos, ou seja, a aquisição de CHA pelos alunos, oriundos da inserção e interação dos indivíduos em uma situação de resolução de problema real do mercado de trabalho, observou-se que as atitudes foram as mais desenvolvidas pela turma. Dentre os principais resultados, os autores consideram importante que o aluno entenda o que significa a nota global da disciplina, bem como as notas de cada elemento do CHA, para que perceba quais elementos devem ser reforçados. Dessa forma, torna-se importante o feedback contínuo por parte do docente durante todo o desenvolvimento do curso.

Tendo como base as mudanças que ocorreram nas expectativas do mercado sobre os graduados em contabilidade, exigindo não apenas conhecimento específico das técnicas contábeis, mas também múltiplas competências e uma visão holística do mundo dos negócios, Barut et al. (2016) verificaram a efetividade do método PBL nos programas de contabilidade em instituições de ensino superior.

Os resultados encontrados por Barut et al. (2016) demonstram que, ao aderir ao método, os estudantes de contabilidade ganham conhecimento na área, adquirem habilidades para resolver problemas, melhoram suas habilidades de comunicação e se tornam mais autoconfiantes. Adicionalmente, também foi verificado que os estudantes avaliaram positivamente a aplicação do método, bem como foram sinceros em suas autoavaliações.

Na perspectiva que o PBL vem sendo uma metodologia crescente no processo de ensinoaprendizagem do curso de Ciências Contábeis, Moreira e Oliveira (2017) avaliaram o nível de aderência das práticas de ensino da contabilidade ao PBL nos cursos de Ciências Contábeis de 26 IES do estado de Minas Gerais.

Como resultados, teve-se uma média de 7,02 pontos, o que é considerado nível médio de aderência das práticas de ensino ao PBL. Dessa forma, os autores concluem que o ensino da contabilidade já possui algumas características do PBL, no entanto, ainda necessita de sistematização e consolidação. As principais deficiências encontradas estão na forma como os conteúdos são transmitidos nos moldes tradicionais de ensino, priorizando a estrutura de palestras e não possibilitando que os alunos participem ativamente do processo avaliativo.

Por meio de um experimento com estudantes do curso de Ciências Contábeis, Hsu, Yen e Lai (2016) investigaram a relação entre o método PBL e os resultados da aprendizagem desses estudantes. Em síntese, os principais resultados demonstram que os scores de resultados dos estudantes do grupo experimental foram superiores aos do grupo de controle. Ademais, também foi percebido que o PBL encorajou a aprendizagem autônoma dos estudantes de contabilidade, bem como propicia aproximar esses de práticas profissionais ainda no âmbito acadêmico.

Por fim, Garnjost e Brown (2018) identificaram a percepção de graduandos da área de gestão acerca de cinco aspectos relacionados ao PBL, sendo eles: aquisição de conhecimentos; resolução de problemas; pensamento crítico; trabalho em equipe e aprendizagem autônoma. Como resultados, não foram percebidas diferenças estatisticamente significativas entre aulas tradicionais ou por meio do PBL para todos os aspectos pesquisados (aquisição de conhecimentos, resolução de problemas, pensamento crítico, trabalho em equipe e aprendizagem autônoma), levantando dúvidas sobre a superioridade da aprendizagem baseada em problemas em comparação aos métodos tradicionais. 


\section{Aspectos Metodológicos}

\subsection{Tipologia da Pesquisa}

O presente estudo caracteriza-se como descritivo quanto ao objetivo, como qualitativo quanto à abordagem do problema e, em relação aos procedimentos, como estudo de caso, definido por Eisenhardt (1989) como uma estratégia de pesquisa que se concentra em entender a dinâmica em um ambiente único. No entanto, apesar deste contexto específico, Stake (1978) ressalta que o objeto-alvo de investigação não precisa ser um único indivíduo ou uma única instituição para ser considerado como caso.

Diante disso, considera-se o estudo de caso como uma estratégia adequada para a análise detalhada da percepção dos mestrandos sobre o método PBL, uma vez que Yin (2015) descreve que o método se diferencia dos demais procedimentos pela profundidade do fenômeno que está sendo estudado.

\subsection{Unidade de Análise}

O estudo foi realizado na UFRN, em que participaram da aplicação prática do PBL, no mês de novembro de 2016, oito discentes da disciplina de Metodologia do Ensino Superior do Mestrado Acadêmico em Ciências Contábeis, possibilitando, assim, que as equipe fossem formadas por quatro participantes, conforme preconiza o método (SOUZA; DOURADO, 2015). Ressalta-se que a unidade de análise do presente estudo foi definida por critério de acessibilidade.

Considera-se importante ressaltar que antes da aplicação do PBL na turma do Mestrado Acadêmico, foi realizado um estudo piloto com cinco discentes da Graduação em Ciências Contábeis, selecionados por acessibilidade, objetivando aprimorar a aplicação do método, bem como o roteiro de entrevista do grupo focal, o que proporcionou benefícios como ajustes da postura dos facilitadores na aplicação do PBL e readequação de alguns questionamentos na entrevista do grupo focal.

\subsection{Características e Etapas do Processo de Aprendizagem na ABP}

A aplicação do método PBL foi mediada por dois alunos do Mestrado Acadêmico em Ciências Contábeis, que não compuseram a amostra do estudo, exercendo a função de professores tutores, com as atribuições de instigar, motivar e ajudar os alunos a tomarem suas próprias decisões, a definirem as regras que norteariam o trabalho do grupo, contribuir com eles na pesquisa dos referenciais importantes na aprendizagem do tema em estudo e orientá-los na elaboração do trabalho final, bem como apoiar aqueles que encontrarem dificuldades durante o processo.

Considerando que no mesmo semestre letivo os mestrandos estavam cursando a disciplina de Contabilidade Societária, o método foi aplicado com base no estudo de Benjamim Júnior (2011), que adaptou o estudo de caso “Qual é o lucro? Quer que dê quanto?” para o PBL, cujo teor relaciona-se com o conteúdo da disciplina de Contabilidade Societária.

A estrutura de consecução das atividades foi composta por sete etapas, conforme descrevem Wood (2003) sendo elas: (i) Esclarecer os termos difíceis ou desconhecidos; (ii) Definir os problemas; (iii) Discussão dos problemas (brainstorm); (iv) Resumo; (v) Formulação dos objetivos de aprendizado; (vi) Pesquisa individual na busca de informações; e (vii) Retorno, integração das informações e resolução do caso. As equipes tiveram o tempo de 40 minutos para operacionalização de cada etapa do PBL.

Visando selecionar os membros dos grupos sem enviesar o processo de definição da amostra, conforme descrito por Ishak e Bakar (2014), os participantes foram definidos de forma aleatória. Para facilitar a interação e aprendizagem, conforme preconizado pelo método, os 
membros foram orientados a arranjarem-se em círculos, conforme carteiras previamente organizadas e dividirem entre si os papéis de líder, secretário-relator e membros.

Em seguida, os tutores apresentaram o contexto problemático a ser resolvido pelos alunos, por meio de texto impresso, de modo a garantir que a investigação desenvolvida pelos alunos alcançasse o objetivo pretendido, que é a aprendizagem do tema investigado (CARVALHO, 2009). Além disso, fizeram a mediação para o cumprimento de todas as etapas do método, por meio de instruções, dicas metodológicas e orientações conceituais que pudessem conduzir as equipes à solução do caso em sala de aula. Após a conclusão das sete etapas realizadas em sala de aula, em um único dia, a equipes formaram um grupo amplo onde puderam apresentar e discutir as soluções encontradas.

Posteriormente, foi realizada uma entrevista em grupo focal, em que as equipes formaram um grupo amplo onde puderam apresentar suas ideias e respostas às ideias dos outros, às experiências e aos eventos colocados pelos tutores, registrando as opiniões e sintetizando as discussões estimuladas pelos tutores, os próprios pesquisadores, e discutir as soluções encontradas (MARTINS; THEÓPHILO, 2007). Nesta etapa, o primeiro tutor assumiu o papel de pesquisador moderador - para focalizar o tema, promover a participação de todos, inibir os monopolizadores da palavra e aprofundar a discussão - , e o segundo tutor assumiu o papel de pesquisador relator, auxiliando o moderador nos aspectos organizacionais e registrando tudo o que viu sobre o processo criativo e interativo (MINAYO, 2010).

O grupo focal foi desenvolvido em três seções: (i) aplicação do PBL na Contabilidade; (ii) competências desenvolvidas com a utilização do método; e (iii) postura do docente na aplicação do PBL, sendo as questões abertas elaboradas com base nos estudos de Heagy e Lehmann (2005), Stanley e Marsden (2012) e Frezatti et al. (2016), sendo o roteiro das questões abertas evidenciado no Quadro 1.

\begin{tabular}{|c|c|c|c|}
\hline Categoria & Pergunta & Constructo & Autores \\
\hline \multirow[t]{2}{*}{$\begin{array}{l}\text { (i) Aplicação do PBL } \\
\text { na Contabilidade }\end{array}$} & $\begin{array}{l}\text { Vocês acreditam que o PBL é uma } \\
\text { metodologia que pode ser aplicada na } \\
\text { contabilidade? Se sim, sob a ótica de que } \\
\text { aspectos? }\end{array}$ & \multirow[t]{2}{*}{$\begin{array}{c}\text { Prática } \\
\text { Profissional }\end{array}$} & $\begin{array}{c}\text { Heagy e } \\
\text { Lehmann (2005) }\end{array}$ \\
\hline & $\begin{array}{l}\text { Vocês acreditam que o problema abordado } \\
\text { reflete a prática profissional do contador? }\end{array}$ & & \multirow{3}{*}{$\begin{array}{c}\text { Stanley e } \\
\text { Marsden (2012) }\end{array}$} \\
\hline \multirow{6}{*}{$\begin{array}{l}\text { (ii) Competências } \\
\text { desenvolvidas com a } \\
\text { utilização do método }\end{array}$} & $\begin{array}{l}\text { Após a utilização do PBL, vocês se sentem } \\
\text { mais confortáveis em lidar com problemas } \\
\text { não estruturados e fatos incompletos, ou não } \\
\text { sentiram diferença nesse aspecto? }\end{array}$ & \multirow{6}{*}{$\begin{array}{l}\text { Conhecimentos, } \\
\text { Habilidades e } \\
\text { Atitudes }\end{array}$} & \\
\hline & $\begin{array}{l}\text { Existiram pontos importantes para a resolução } \\
\text { do problema que vocês desconheciam? Se } \\
\text { sim, qual a percepção de vocês sobre o fato de } \\
\text { serem agentes ativos no processo de } \\
\text { aprendizagem? }\end{array}$ & & \\
\hline & $\begin{array}{l}\text { Vocês acreditam que a habilidade de resolver } \\
\text { problemas foi otimizada com o método? }\end{array}$ & & $\begin{array}{l}\text { Frezatti et al. } \\
\qquad(2016)\end{array}$ \\
\hline & $\begin{array}{l}\text { Vocês acreditam outras habilidades ou } \\
\text { atitudes foram desenvolvidas com a aplicação } \\
\text { do método, se sim quais? }\end{array}$ & & \\
\hline & $\begin{array}{l}\text { E em relação aos conhecimentos sobre o tema } \\
\text { em questão? }\end{array}$ & & \\
\hline & $\begin{array}{l}\text { Qual a opinião de vocês sobre o trabalho em } \\
\text { equipe? }\end{array}$ & & $\begin{array}{c}\text { Stanley e } \\
\text { Marsden (2012) }\end{array}$ \\
\hline
\end{tabular}


Quadro 1 - Roteiro de Perguntas do Grupo Focal

\begin{tabular}{|c|l|c|c|}
\hline Categoria & \multicolumn{1}{|c|}{ Pergunta } & Constructo & Autores \\
\hline & $\begin{array}{l}\text { Vocês acreditam que o trabalho em grupo foi } \\
\text { bem-sucedido? Se sim, quais fatores } \\
\text { influenciaram para esse sucesso, ou se não, o } \\
\text { que causou o insucesso? }\end{array}$ & & \\
\hline $\begin{array}{c}\text { (iii) Postura do docente } \\
\text { na aplicação do PBL }\end{array}$ & $\begin{array}{l}\text { Qual a sua percepção sobre a postura do } \\
\text { professor como facilitador? }\end{array}$ & $\begin{array}{c}\text { Postura do } \\
\text { Docente }\end{array}$ & $\begin{array}{c}\text { Heagy e } \\
\text { Lehmann (2005) }\end{array}$ \\
\hline
\end{tabular}

Fonte: Elaborado pelos autores

Concluída a entrevista em grupo focal, foi aplicado um questionário com perguntas fechadas, elaborado pelos autores, visando coletar informações relacionadas ao perfil dos participantes, evidenciadas no Quadro 2.

Quadro 2 - Participantes da Pesquisa
\begin{tabular}{|c|c|c|c|c|}
\hline $\begin{array}{c}\text { Código do } \\
\text { Entrevistado }\end{array}$ & Gênero & Faixa Etária & Área de Atuação & $\begin{array}{c}\text { Experiência com } \\
\text { o método PBL }\end{array}$ \\
\hline M1 & Feminino & 21 a 30 Anos & Não Atua na Área & Não \\
\hline M2 & Masculino & 21 a 30 Anos & Docência, Auditoria e Perícia Contábil & Não \\
\hline M3 & Feminino & 21 a 30 Anos & Contabilidade Governamental & Não \\
\hline M4 & Feminino & 21 a 30 Anos & Não Atua na Área & Não \\
\hline M5 & Feminino & 21 a 30 Anos & Não Atua na Área & Não \\
\hline M6 & Feminino & 21 a 30 Anos & Contabilidade Societária & Não \\
\hline M7 & Masculino & 31 a 40 Anos & Docência & Não \\
\hline M8 & Feminino & 21 a 30 Anos & Docência e Contabilidade Societária & \\
\hline
\end{tabular}

Fonte: Dados da Pesquisa

Segundo Eisenhardt (1989), os estudos de caso devem combinar métodos de coleta de dados, como entrevistas, questionários, documentos e observações. Nesse sentido, a realização do grupo focal foi importante para triangulação entre os achados da observação participante dos autores, a solução do problema apresentada pelas equipes e a opinião dos alunos quanto à efetividade do método.

Para tanto, os dados primários obtidos na entrevista do grupo focal foram transcritos na íntegra para um arquivo digital do software Microsoft Word $2010 \AA$. Ressalta-se que, posteriormente à transcrição do grupo focal, o texto foi disponibilizado aos participantes do estudo, que revisaram e confirmaram que os trechos estavam condizentes com suas versões.

\subsection{Procedimentos de Análise de dados}

Após a transcrição, adotou-se a técnica de análise de conteúdo que, de acordo com Bardin (2011) pode ser utilizada para analisar em profundidade cada expressão específica de indivíduos ou grupos.

Para identificar as conexões, códigos e categorias existentes nas transcrições das entrevistas, realizou-se o processo de codificação aberta e axial das unidades de significado. De acordo com Flick (2009), a codificação aberta é realizada com o objetivo de segmentar os dados, para que posteriormente seja realizada a codificação axial, que se refere ao aprimoramento e à diferenciação das categorias resultantes da codificação aberta.

O processo de codificação foi realizado no Software ATLAS.ti 7®, em que a codificação aberta propiciou segmentar as unidades de significado nos códigos referentes à percepção dos discentes sobre a aplicabilidade, os benefícios, as limitações, os conhecimentos, habilidades e atitudes desenvolvidos, bem como sobre a postura do docente nessa aplicação. Posteriormente, 
através da codificação axial, os códigos foram elencados nas três categorias do constructo da pesquisa: (i) aplicação do PBL na Contabilidade; (ii) competências desenvolvidas com a utilização do método; e (iii) postura do docente na aplicação do PBL.

Conforme critérios para o julgamento da qualidade nos estudos de caso estabelecidos por Yin (2015), observa-se que, do ponto de vista do rigor metodológico, os constructos que serviram de base para a realização deste estudo foram também utilizados por outros autores (FREZATTI et al., 2016; HEAGY; LEHMANN, 2005; STANLEY; MARSDEN, 2012), demonstrando, assim, a utilização de diversas fontes de evidências como forma de estabelecer medidas operacionais corretas para os conceitos que estão fundamentando o estudo.

No que tange a confiabilidade de um estudo de caso, Yin (2015) sugere a utilização de um protocolo do estudo de caso como forma de garantir que os procedimentos realizados na pesquisa possam ser repetidos. Diante disso, como forma de assegurar a confiabilidade, o presente estudo teve seus procedimentos guiados por um protocolo de estudo de caso, além do banco de dados referente às entrevistas transcritas e analisadas no software ATLAS.ti 7®.

Quanto aos aspectos éticos da pesquisa, foram firmados previamente o Termo de Autorização para Gravação de Voz e o Termo de Consentimento Livre e Esclarecido, que é um documento de caráter explicativo, onde são abordadas todas as questões relativas ao estudo que possam estar relacionadas à decisão do sujeito e, assim, garantir sua participação voluntária (SOUZA et al., 2013).

\section{Análise de Resultados}

\subsection{Aplicabilidade do PBL na Contabilidade}

A primeira seção da entrevista em grupo focal visa identificar a percepção dos participantes da pesquisa sobre a aplicação do PBL na Contabilidade. Nessa perspectiva, verifica-se que a participante M1 considera que o método pode ser aplicável a diversas disciplinas do curso de Ciências Contábeis, confirmando, assim, a perspectiva de Manaf, Ishak e Hussin (2011) e Araújo e Slomski (2013). No entanto, apesar da aplicabilidade do PBL propiciar resultados satisfatórios quando comparado à metodologia tradicional de ensino, o respondente M2 evidencia que o método ainda é pouco utilizado, corroborando, assim, com Stanley e Marden (2012) e Martins e Espejo (2015), que afirmam que o PBL ainda é uma abordagem incipiente no ensino da Contabilidade.

Figura 1 - Aplicabilidade do PBL na Contabilidade sob a Perspectiva dos Discentes

\begin{tabular}{ll}
\hline $\begin{array}{l}\text { Eu acredito que o método dá para ser } \\
\text { aplicado. E, acredito que na maioria das } \\
\text { disciplinas. Porque é possivel até estudar } \\
\text { contabilidade básica ou intermediária } \\
\text { fazendo esse tipo de problema. }\end{array}$ \\
\hline [2:1] Participante $-\mathrm{M} 1$
\end{tabular}

Fonte: Dados da pesquisa

Levando em consideração que o PBL ainda não é utilizado amplamente no curso de Ciências Contábeis, a participante M3 descreve que, além da necessidade de quebrar o paradigma do docente como detentor do conhecimento e alunos como receptores de informação, também tem-se como aspecto limitante o escasso tempo dos professores para planejamento das atividades, conforme evidenciado na Figura 2. 
Figura 2 - Limitação do Método PBL no Ensino de Contabilidade

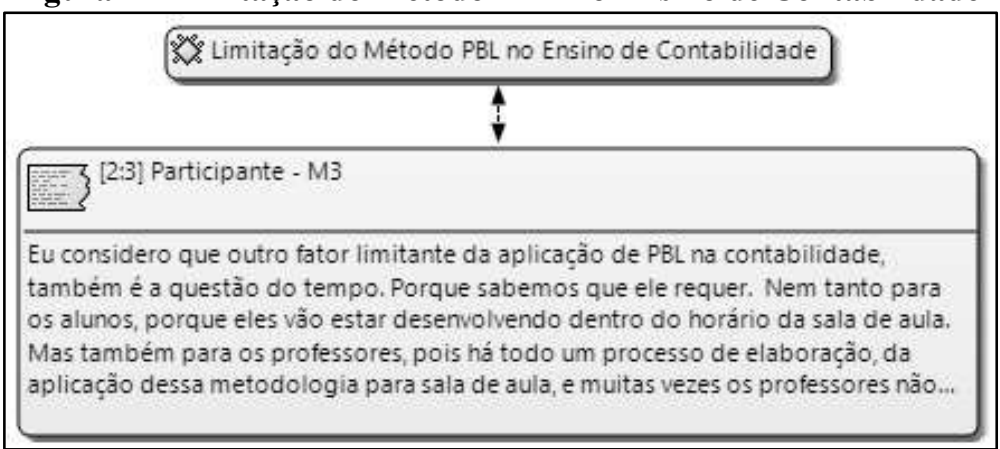

Fonte: Dados da pesquisa

No entanto, ressalta-se que o PBL não só demanda planejamento e execução das atividades por parte do docente no horário extra-classe, mas, também, dos discentes, que desenvolvema capacidade do estudo autônomo, tendo em vista a necessidade da realização de pesquisas e reuniões de equipe em horários paralelos para a realização das atividades propostas no método.

De forma complementar, os participantes M5 e M8 descrevem que a ausência de colaboração por parte dos componentes dos grupos no decorrer das atividades, assim como o respeito pela opinião dos outros, podem ser considerados fatores limitantes para o sucesso da aprendizagem.

\section{Figura 3 - Limitações do Método PBL no Ensino de Contabilidade}

Há nosso amadurecimento também, a gente estava, como é uma turma de
mestrado, talvez até disposta a passar por essas coisas. Mas quando vocé vai numa
turma de graduação, tem aquele problema de que aqueles alunos às vezes nảo
estão pré-dispostos a passar por isso. Então acontece de só uma parte do grupo
trabalhar, outro não trabalhar. Que em trabalho em grupo na graduação a gente vê
que acontece muito isso, que um fica com o fardo e o outro leva à frente.

Fonte: Dados da pesquisa

Apesar das dificuldades de implementação do método na percepção dos discentes, também foram elencados benefícios da utilização do PBL no ensino da Contabilidade, como trazer a prática do mercado para o âmbito acadêmico e propiciar a aquisição de conhecimentos interdisciplinares, conforme demonstrado na Figura 4.

\section{Figura 4 - Benefícios do Método PBL no Ensino de Contabilidade}

Considero que o método é muito
válido para trazer a prática do
mercado para dentro da sala de aula

Fonte: Dados da pesquisa

Este achado corrobora com Stanley e Marsden (2012), que descrevem que o PBL é um veículo ideal para incorporar o contexto da vida real contábil à sala de aula, assim como com 
Enemark e Kjaersdam (2009) que consideram o PBL como a ponte que aproxima o ensino da prática empresarial, reduzindo o gap entre a teoria e a prática na sala de aula.

\subsection{Competências Desenvolvidas com a Utilização do PBL}

Compreendidas como o conjunto de conhecimentos, habilidades e atitudes necessárias ao futuro profissional de Contabilidade para atuar no contexto empresarial, conforme descrevem Martins e Espejo (2015), as competências desenvolvidas com a utilização do PBL foram investigadas no presente estudo. Nessa perspectiva, os discentes M3 e M2 reconhecem que os principais conhecimentos desenvolvidos através da aplicação do problema proposto por Benjamim Júnior (2011) foram nas áreas de Contabilidade Gerencial, Contabilidade Societária e Responsabilidade Social Corporativa, considerando os aspectos éticos envolvidos no problema, conforme demonstra a Figura 5.

Figura 5 - Conhecimentos Desenvolvidos com a Utilização do PBL

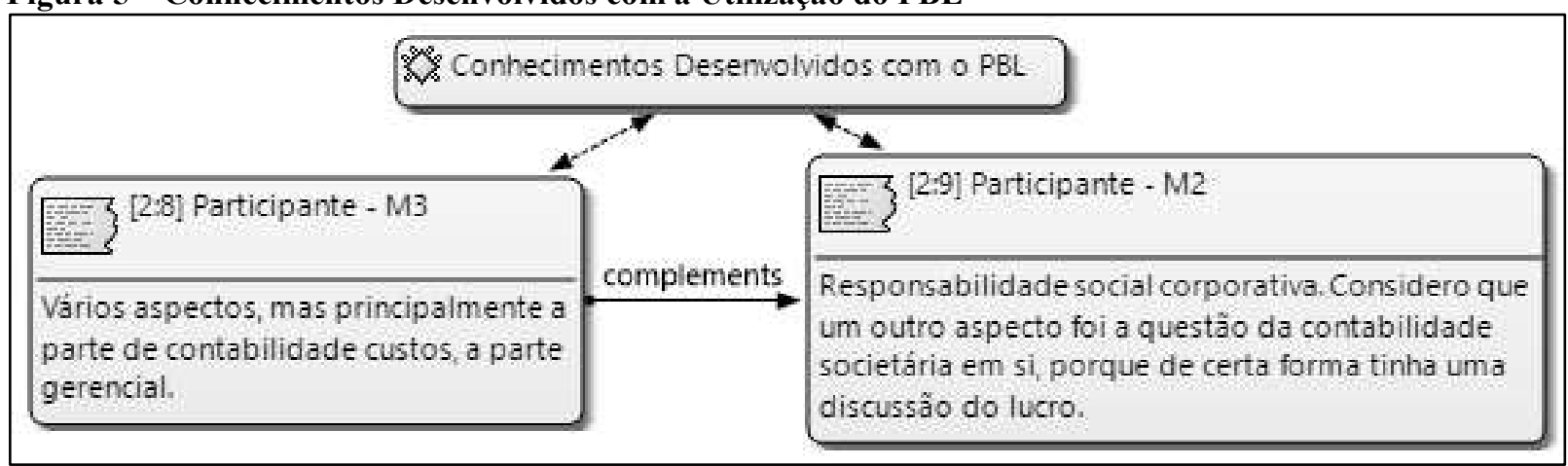

Fonte: Dados da pesquisa

Tendo em vista que um dos principais objetivos do PBL é propiciar que os discentes desenvolvam conhecimentos flexíveis que possam ser aplicados na resolução de problemas, conforme evidencia Hmelo-Silver (2013), considera-se que os objetivos de aprendizagem do problema foram alcançados sob a ótica dos conhecimentos desenvolvidos com a utilização do método. De forma complementar, observa-se que o problema proposto abrange aspectos interdisciplinares, conforme preconiza a literatura (DOBSON; TOMKINSON, 2012; DUCH, 2001; HMELO-SILVER, 2004).

No tocante às habilidades, percebe-se que, sob a ótica da discente M5, a utilização do PBL proporcionou o desenvolvimento de habilidades de solução de problemas de ordem prática e profissional, corroborando, assim, com outros estudos já realizados na área (FREZATTI et al., 2016; MARTINS; ESPEJO; FREZATTI, 2015; RIBEIRO, 2010; SOCKALINGAM, 2010).

Figura 6 - Habilidades Desenvolvidas com a Utilização do PBL

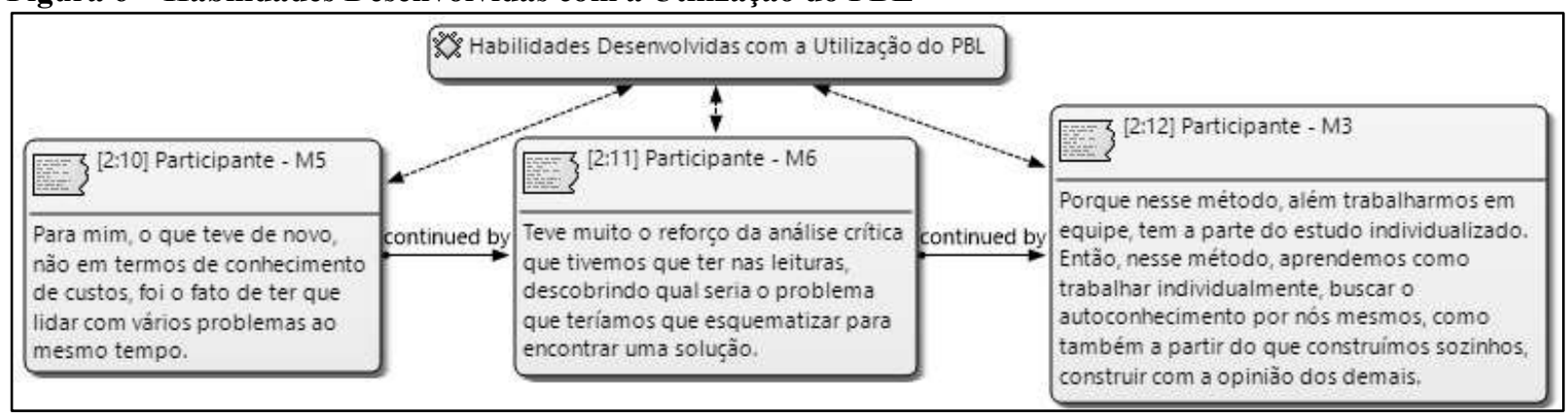

Fonte: Dados da pesquisa 
Sob a ótica da participante M6, o método também propiciou desenvolver a habilidade de análise crítica, tendo em vista que o problema estimula o pensamento, a análise e o raciocínio, confirmando, assim, a perspectiva de Sockalingam e Schmidt (2011), Pinheiro, Sarrico e Santiago (2011), Martins, Espejo e Frezatti (2015) e Guedes, Andrade e Nicolini (2015).

De forma complementar, a discente M3 considera que além do trabalho em equipe, levando em consideração que todos os membros atuam conjuntamente para contribuir para o sucesso da aprendizagem, também foram desenvolvidas as habilidades de estudo independente e trabalho autorregulado, tendo em vista que os discentes aprendem a aprender, sendo responsáveis pela sua própria aquisição do conhecimento. Este resultado está de acordo com as pesquisas de Ribeiro (2010), Martins, Espejo e Frezatti (2015) e Frezatti et al. (2016), que identificaram que, através do PBL, os discentes desenvolveram as habilidades de estudo independente e trabalho autorregulado.

No tocante ao estudo independente e ao trabalho autorregulado, Martins, Espejo e Frezatti (2015) afirmam que a sobrecarga de informação na aplicação do PBL pode tornar os discentes inseguros quanto à seleção de informações úteis e relevantes. Os autores também consideram necessário trabalhar o aluno para que ele conheça o método e seus benefícios, como forma de uma melhor adaptação ao ambiente de trabalho autorregulado.

Por fim, os participantes M5 e M2 consideram que o método contempla, na formação acadêmica, os benefícios proporcionados pela comunicação, incluindo a capacidade de síntese do conteúdo, conforme descrito na Figura 7.

Figura 7 - Habilidades Desenvolvidas com a Utilização do PBL

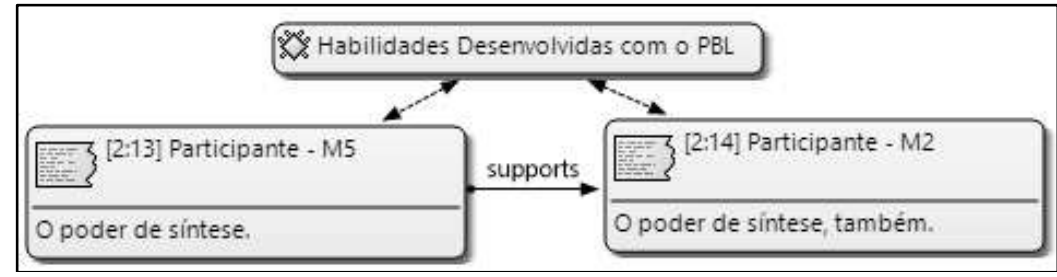

Fonte: Dados da pesquisa

Além de estar em consonância com os estudos de Ribeiro (2010), Sockalingam (2010) e Manaf, Ishak e Hussin (2011), a otimização do poder de síntese, que está relacionada com a comunicação, foi otimizada na resolução do problema, pois, ao longo das sete etapas, os demais membros de cada grupo auxiliavam o relator na elaboração dos relatórios. Além disso, a apresentação do relatório consolidado na etapa final também foi relevante para o desenvolvimento da habilidade de síntese de informações.

Figura 8 - Atitudes Desenvolvidas com a Utilização do PBL

Considero também a colaboração. Porque se não for colaborativo com os membros
da sua equipe, nâo se consegue desempenhar o trabalho. Năo se consegue seguir
sozinho. Então, essa questão de estar comentando: "olha, eu pesquisei isso", "olha,
eu olnei isso". E, nessa questão, pelo menos, nossa equipe trabalhou bastante.

Fonte: Dados da pesquisa

Em relação às atitudes, a participante M1 descreve que os aspectos de 
colaboração/cooperação, que consiste em contribuir para os objetivos do grupo, foram desenvolvidos com a aplicação do PBL, estando, assim, de acordo com as pesquisas de Hansen (2006), Savery (2006), Martins, Espejo e Frezatti (2015) e Frezatti et al. (2016). Nessa perspectiva, Martins, Espejo e Frezatti (2015) elencam a importância de se verificar os estilos de aprendizagem dos alunos, como forma de possibilitar uma melhor adaptação dos alunos no ambiente de aprendizagem colaborativa.

Figura 9 - Competências Desenvolvidas com a Utilização do PBL

\begin{tabular}{|c|c|c|}
\hline & \multicolumn{2}{|c|}{ (3) Competências Desenvolvidas com a Utilização do Método } \\
\hline & $\frac{\pi}{4}$ & \\
\hline $\begin{array}{l}\text { 2.: Conhecimentos } \\
\text { Desenvolvidos com o PBL }\end{array}$ & $\begin{array}{l}\text { 27. Habilidades } \\
\text { Desenvolvidas com o PBL }\end{array}$ & $\begin{array}{l}\text { 2. Atitudes Desenvolvidas } \\
\text { com o PBL }\end{array}$ \\
\hline $\begin{array}{l}\text { Contabilidade gerencial, } \\
\text { Contabilidade societária } \\
\text { e Resposabilidade social } \\
\text { corporativa }\end{array}$ & $\begin{array}{l}\text { Solução de problema, } \\
\text { Análise crítica, Estudo } \\
\text { independente, Trabalho } \\
\text { autorregulado e } \\
\text { Comunicação }\end{array}$ & $\begin{array}{l}\text { Colaboração/ } \\
\text { Cooperação }\end{array}$ \\
\hline
\end{tabular}

Fonte: Dados da pesquisa

Em síntese, observa-se que os principais conhecimentos desenvolvidos com a utilização do problema proposto por Benjamim Júnior (2011) foram nas áreas de Contabilidade Gerencial, Contabilidade Societária e Responsabilidade Social Corporativa. Em relação às habilidades, destacam-se a solução de problemas, análise crítica, estudo independente, trabalho autorregulado e comunicação. Por fim, no tocante às atitudes, a colaboração/cooperação foi descrita, na entrevista em grupo focal, como desenvolvida na utilização do método.

Diante disso, com base na percepção dos participantes da pesquisa, depreende-se que o método PBL apresenta uma potencialidade para desenvolver conhecimentos, habilidades e atitudes de forma integrada, otimizando, assim, o processo de ensino-aprendizagem, conforme evidenciado por Guedes, Andrade e Nicolini (2015).

\subsection{Postura do Docente na Aplicação do PBL}

A atividade que o professor desempenha durante a aplicação do PBL deve ser a de facilitador/tutor nas várias fases, não dando respostas prontas, mas apenas mediando os estudantes na busca de soluções (ALMEIDA; BATISTA, 2013; FREZATTI et al., 2016; GUEDES; ANDRADE; NICOLINI., 2015). Dessa forma, em relação à postura do docente no processo de ensino-aprendizagem, os participantes descrevem a importância do docente como mediador nas etapas do PBL, conforme demonstra a Figura 10.

Figura 10 - Postura do Docente na Aplicação do PBL

Considero que é importante também a questão do papel
do professor como mediador. Se os mediadores ficassem
distantes, talvez não conseguissemos caminhar. Mas só em
dizer 'é por aí, valeu!", vocé está no caminho!" Isto é um
incentivo. Considero que além de mediador, o papel do
docente é de incentivador. Isso é importante.

Fonte: Dados da pesquisa 
De acordo com a percepção dos participantes, a postura adotada pelos mediadores foi de desafiador, realizando perguntas de envolvimento, de facilitador, ajudando os alunos a resolver problemas com a dinâmica interpessoal, assim como de diretor, tendo em vista os aspectos de reflexão, conforme evidencia Newman (2005). Diante disso, o papel do professor como mediador e incentivador na resolução dos problemas está de acordo com o estudo de Frezatti e Silva (2014), que afirmam que o método requer maior direcionamento, estímulo e cobrança do andamento dos trabalhos por parte do docente.

Figura 11 - Postura do Docente na Aplicação do PBL

\begin{tabular}{ll|} 
Considero que a principal característica de docente facilitador é muito \\
motivacional. No momento que os tutores ficavam nos instigando \\
com aquelas perguntas, com aqueles questionamentos, acabava por \\
nos motivar a pesquisar e buscar solucionar o problema cada vez mais. \\
$\begin{array}{l}\text { Para mim, foi assim. Eu me lembro de que quando o tutor disse-me da } \\
\text { variação, que eu estava chegando perto, enquanto eu não encontrei a } \\
\text { relaçăo correta, eu não sosseguei. Por què? Porque eu tive o estimulo } \\
\text { de que eu estava no caminho certo, o que me motivou. }\end{array}$
\end{tabular}

Fonte: Dados da pesquisa

De forma complementar, os participantes M3 e M1 ressaltam a importância do tutor incentivar os discentes na realização das atividades propostas, estando, assim, em consonância com Frost (1996), que descreve que a principal função do tutor é instigar os estudantes a pesquisar e refletir a respeito do conhecimento que já possuem sobre o tema aplicado e a buscar novos objetivos nesta aprendizagem.

Com base nos resultados encontrados, considera-se que um dos grandes desafios do PBL é fazer com que o professor se adeque ao novo papel no processo de ensino-aprendizagem, o qual espera que os educadores sejam orientadores, coaprendizes e facilitadores da construção do conhecimento, conforme evidenciam Almeida e Batista (2013) e Martins e Espejo (2015).

\section{Considerações Finais}

Considerando a importância do PBL como metodologia ativa de aprendizagem, o presente estudo teve como objetivo analisar a percepção dos mestrandos do Programa de PósGraduação em Ciências Contábeis da Universidade Federal do Rio Grande do Norte (UFRN) sobre a aplicabilidade, as competências desenvolvidas e a postura docente no método ProblemBased Learning (PBL) aplicado ao ensino de Contabilidade.

O estudo foi realizado na UFRN, em que participaram da aplicação prática do PBL, no mês de novembro de 2016, oito discentes da disciplina de Metodologia do Ensino Superior, do Mestrado Acadêmico em Ciências Contábeis. A aplicação do método PBL foi mediada por dois alunos do Mestrado Acadêmico em Ciências Contábeis, sendo realizada com base no problema “Qual é o lucro? Quer que dê quanto?”, proposto por Benjamim Júnior (2011).

Após a conclusão das etapas do PBL, foi realizada uma entrevista em grupo focal composta por três seções: (i) aplicação do PBL na Contabilidade; (ii) competências desenvolvidas com a utilização do método; e (iii) postura do docente na aplicação do PBL, em que os dados primários obtidos foram analisados através da técnica de análise de conteúdo, utilizando-se o Software ATLAS.ti 7® para o processo de codificação.

Os resultados encontrados evidenciaram que, na perspectiva dos discentes, o método pode ser aplicável a diversas disciplinas do curso de Ciências Contábeis, proporcionando 
benefícios como a aquisição de conhecimentos interdisciplinares, além de trazer a prática do mercado para o âmbito acadêmico.

Em relação às competências desenvolvidas pelo método, observou-se que os principais conhecimentos desenvolvidos com a utilização do problema proposto foram nas áreas de Contabilidade Gerencial, Contabilidade Societária e Responsabilidade Social Corporativa. Em relação às habilidades, destacaram-se a solução de problemas, análise crítica, estudo independente, trabalho autorregulado e comunicação e, por fim, no tocante às atitudes, a colaboração/cooperação foi descrita, na entrevista em grupo focal, como desenvolvida na utilização do método.

No tocante à postura do docente no processo de ensino-aprendizagem, os participantes descreveram a importância do docente como mediador nas etapas do PBL. De forma complementar, também se ressaltou a importância de o tutor incentivar os discentes na realização das atividades propostas.

De forma geral, percebeu-se que, embora existam dificuldades e desafios a serem superados quando se trata da implementação do PBL, sobretudo pela resistência na superação da metodologia tradicional de ensino, o PBL é um método eficaz de aprendizagem, principalmente porque é centrado no aluno como sujeito ativo do processo, que busca o aprendizado de forma autônoma com base em problemas que refletem a vida profissional.

Como limitações do estudo, cita-se o curto espaço de tempo para a vivência prática dos mestrandos com o PBL, haja vista que o método foi implementado em um curto espaço de tempo, pois a disciplina já possuía um cronograma definido, em que outras abordagens também foram investigadas, como o Case-Based Learning, Project-Based Learning e a Aprendizagem Colaborativa.

Diante disso, sugere-se que novas pesquisas averiguem o PBL considerando um maior prazo para que os discentes tenham uma maior experiência com a solução de problemas, além do utilizado no presente estudo, bem como implementar o método considerando um grupo de controle, a fim de realizar um comparativo da percepção dos mestrandos acerca das competências desenvolvidas pelo PBL e pelo método tradicional de ensino. De forma complementar, também sugere-se identificar se há relação entre o estilo de aprendizagem de cada aluno e a aquisição de determinadas competências através da utilização do método PBL.

\section{Referências}

ALMEIDA, E. G.; BATISTA, N. A. Desempenho docente no contexto PBL: Essência para aprendizagem e formação médica. Revista Brasileira de Educação Médica, v. 37, n. 2, p. 192-201, 2013.

ANDREOLI, F. N.; BEHRENS, M. A.; TORRES, P. L. Metodologia de projeto no paradigma da complexidade aplicada em disciplina de curso superior. Revista Contrapontos, v. 12, n. 2, 179-188, 2012.

ARAÚJO, A. M. P.; SLOMSKI, V. G. Active learning methods - An analysis of applications and experiences in Brazilian accounting teaching. Creative Education, v. 4, n. 12, p. 20-27, 2013.

ARAÚJO, U. F.; ARANTES, V. A. Comunidade, conhecimento e resolução de problemas: o projeto acadêmico da USP Leste. In: ARAÚJO, U. F.; SASTRE, G. (Orgs.). Aprendizagem baseada em problemas no ensino superior. São Paulo: Summus, 2009. p. 101-122.

BARDIN, L. Análise de Conteúdo. São Paulo: Edições 70, 2011. 
BARUT, M. et al. Problem-Based Learning in Accountancy: An Empirical Study. IOSR Journal of Research \& Method in Education, v. 6, n. 6, p. 50-58, 2016.

BENJAMIM JÚNIOR, V. Teoria da complexidade e contabilidade: estudo da utilização da aprendizagem baseada em problemas como abordagem complexa no ensino da contabilidade. 2011. 261f. Dissertação (Mestrado em Ciências Contábeis) - Universidade de São Paulo, São Paulo, 2011.

BLANCO, F. J; LATORRE, M. J. La apuesta por la excelencia en la formación práctica universitaria de futuros profesores. Estudios sobre Educación, n. 15, p. 7-31, 2008.

BRETON, G. Some empirical evidence on the superiority of problem-based learning (PBL) method. Accounting Education, v. 8, p. 1-12, 1999.

CARVALHO, C. J. A. O Ensino e a Aprendizagem das Ciências Naturais através da Aprendizagem Baseada na Resolução de Problemas: um estudo com alunos de $9^{\circ}$ ano, centrado no tema Sistema Digestivo. 2009. 276f. Dissertação de Mestrado (Mestrado em Educação) - Universidade do Minho, 2009.

CÓRIA-SABINI, M. A. A aplicação de teorias psicológicas ao planejamento e avaliação do processo de ensino-aprendizagem. Revista psicopedagogia, v. 20, n. 62, p. 162-172, 2003.

DECKER, I. R.; BOUHUIJS, P. A. J. Aprendizagem baseada em problemas e metodologia da problematização: identificando e analisando continuidades e descontinuidades nos processos de ensino-aprendizagem. In: ARAÚJO, U. F.; SASTRE, G. (Orgs.). Aprendizagem baseada em problemas no ensino superior. São Paulo: Summus, 2009. p. 177-204.

DEELMAN, A.; HOEBERIGS, B. A ABP no contexto da Universidade de Maastricht. In: ARAÚJO, U. F.; SASTRE, G. (Orgs.). Aprendizagem baseada em problemas no ensino superior. São Paulo: Summus, 2009. p. 79-100.

DOBSON, H; TOMKINSON, C. B. Creating sustainable development change agents through problem-based learning: Designing appropriate student PBL projects. International Journal of Sustainability in Higher Education, v. 13 n. 3, p.263 - 278, 2012.

https://doi.org/10.1108/14676371211242571

DOCKTER, D. L. Problem-based learning in accounting. American Journal of Business Education, v. 5, n. 5, p. 547-554, 2012.

DUCH, B. J. Writing problems for deeper understanding. In: DUCH, B. J.; GROH, S. E.; ALLEN, D. E. The power of problem-based learning: a practical "how to" for teaching undergraduate courses in any discipline. Virginia: Stylus Publishing, 2001. p. 47-53.

DUCH, B. J.; GROH, S. E.; ALLEN, D. E. Why problem-based learning? A case study of institutional change in undergraduate education. In: DUCH, B. J.; GROH, S. E.; ALLEN, D. E. The power of problem-based learning: a practical "how to" for teaching undergraduate courses in any discipline. Virginia: Stylus Publishing, 2001. p. 3-12.

EISENHARDT, K. M. Building Theories from Case Study Research. The Academy of Management Review, v. 14, n. 4, p. 532-550, 1989. https://doi.org/10.5465/amr.1989.4308385 
ENEMARK, S.; KJAERSDAM, F. A ABP na teoria e na prática: a experiência de Aalborg na inovação do projeto no ensino universitário. In: Araújo U. F.; SASTRE, G. (Orgs.).

Aprendizagem baseada em problemas no ensino superior. São Paulo: Summus, p. 17-42, 2009.

FLICK, U. Introdução à pesquisa qualitativa. 3 ed. Porto Alegre: Artmed, 2009.

FORTIN, A; LEGAULT, M. Development of Generic Competencies: Impact of a Mixed Teaching Approach on Students' Perceptions, Accounting Education, v. 19, n.1, p. 93-122, 2010. https://doi.org/10.1080/09639280902888195

FREIRE, P. Pedagogia da autonomia: saberes necessários à prática educativa. São Paulo: Paz e Terra, 1996.

FREIRE, P. Pedagogia do oprimido. 17. ed. Rio de Janeiro: Paz e Terra, 1987.

FREZATTI, F. et al. Análise do desempenho de alunos na perspectiva do "CHA" em disciplina utilizando PBL: o que significa a síntese? Revista de Contabilidade e Organizações, v. 26, p. 4-19, 2016.

FREZATTI, F.; MARTINS, D. B. PBL ou PBL's: a customização do mecanismo de aprendizagem baseada em problemas na educação contábil. Revista de Graduação USP, v. 1, n. 1, p. 25-34, 2016.

FREZATTI, F; SILVA, S. C. Prática versus incerteza: como gerenciar o estudante nessa tensão na implementação de disciplina sob o prisma do PBL? Revista Universo Contábil, v. 10, p. 28-46, 2014.

FROST, M. An analysis of the scope and the value of problem-based learning in the education of health care professionals. Journal of Advanced Nursing, v. 24, n.5, p. 10471053, 1996. https://doi.org/10.1111/j.1365-2648.1996.tb02942.x

GARNJOST, P; BROWN, S. M. Undergraduate business students' perceptions of learning outcomes in problem based and faculty centered courses. The International Journal of Management Education, v. 16, n. 1, p. 121-130, 2018.

https://doi.org/10.1016/j.ijme.2017.12.004

GUEDES, K. L.; ANDRADE, R. O. B; NICOLINI, A. M. A avaliação de estudantes e professores de administração sobre a experiência com a aprendizagem baseada em problemas. Administração: Ensino e Pesquisa, v. 16, n. 1, p. 71-100, 2015.

HANSEN, J. D. Using problem-based learning in accounting. Journal of Education for Business, v. 81, n. 4, p. 221-224, 2006. https://doi.org/10.3200/JOEB.81.4.221-224

HARRIS, S. La dimensión internacional de la educación: entre el modelo económico y el cultural. Estudios sobre Educación, n. 15, p. 87-101, 2008.

HEAGY, C. D.; LEHMANN, C. M. Is PBL an improved delivery method for the accounting curriculum? Advances in Accounting Education, v. 7, p. 221-251, 2005.

HMELO-SILVER, C. E. Creating a learning space in problem-based learning.

Interdisciplinary Journal of Problem-Based Learning, v. 7, n. 1, p. 24-39, 2013. 
https://doi.org/10.7771/1541-5015.1334

HMELO-SILVER, C. E. Problem-based learning: what and how do students learn?

Education Psychology Review, v. 16, n. 3, p. 235-266, Set. 2004.

HSU, C.; YEN, S.; LAI, W. The Effect of Problem-Based Learning on Learning Outcomes of Accounting Students. Asian Journal of Finance \& Accounting, v. 8, n. 2, p. 135-154, 2016.

ISHAK, N. M.; BAKAR, A. Y. A. Developing sampling frame for case study: challenges and conditions. World Journal of Education, v. 4, n. 3, p. 29-35, 2014.

JOHNSTONE, K. M.; BIGGS, S. F. Problem-based learning: introduction, analysis, and accounting curricula implications. Journal of Accounting Education, v. 16, n. 3/4, p. 407 427,1998

LA TAILLE, Y. Desenvolvimento do juízo moral. In: MACEDO, L. (Colab.). Jean Piaget. Coleção memória da pedagogia. n. 1. Rio de Janeiro: Ediouro; Segmentto-Duetto, 2005. p. 76-88.

MANAF, N. A. A.; ISHAK, Z.; HUSSIN, W. N. W. Application of problem-based learning $(\mathrm{PBL})$ in a course on financial accounting principles. Malaysian Journal of Learning and Instruction, v. 8, p. 21-47, 2011.

MARTÍNEZ-OTERO, Valentín. Teoria e prática da educação. Natal: EDUFRN, 2012.

MARTINS, D. B.; ESPEJO, M. M. S. B. Problem Based Learning - PBL no Ensino de Contabilidade: Guia Orientativo para Professores e Estudantes da Nova Geração. São Paulo: Atlas, 2015.

MARTINS, D. B.; ESPEJO, M. M. S. B.; FREZATTI, F. Problem-Based Learning no Ensino de Contabilidade Gerencial: Relato de uma Experiência Brasileira. Revista de Educação e Pesquisa em Contabilidade, v. 9, n. 4, p. 430-452, 2015.

MARTINS, G. A.; THEÓPHILO, C. R. Metodologia da investigação científica para ciências sociais aplicadas. São Paulo: Atlas, 2007.

MIRANDA, C. S. Ensino de contabilidade gerencial: uma análise comparativa de percepções de importância entre docentes e profissionais, utilizando as dimensões de atividades, artefatos e competências. 2010. Tese (Doutorado em Ciências Contábeis) Faculdade de Economia, Administração e Contabilidade, Universidade de São Paulo, São Paulo-SP, 2010.

MINAYO, M.C.S. (Org.). Pesquisa Social: teoria, método e criatividade. 29 ed.Petrópolis, RJ: Vozes, 2010.

MOREIRA, M. A.; OLIVEIRA, N. G. A Utilização da Aprendizagem Baseada em Problemas em Cursos de Graduação de Ciências Contábeis. Revista de Gestão e Contabilidade da UFPI, v. 4, n. 2, p. 39-55, 2017.

NEWMAN, M. J. Problem-based learning: an introduction and overview of the key features of the approach. Journal of Veterinary Medical Education, v. 32, n. 1, p. 12-20, 2005. https://doi.org/10.3138/jvme.32.1.12 
OLIVEIRA, R. M. Problem Based Learning como estratégia de ensino: diagnóstico da para a aplicabilidade no curso de Ciências Contábeis da Universidade Federal do Paraná. 2015. 163f. Dissertação de Mestrado (Contabilidade) - Universidade Federal do Paraná, 2015.

PIAGET, J. Problemas de psicologia genética. Rio de Janeiro: Forense, 1973.

PINHEIRO, M. M.; SARRICO, C. S.; SANTIAGO, R. A. Competências de autodesenvolvimento e metodologias PBL num curso de contabilidade: perspectivas de alunos, docentes, diplomados e empregadores. Revista Lusófona de Educação, v. 17, p. 147$166,2011$.

PINHO, S. T. et al. Método situacional e sua influência no conhecimento tático processual de escolares. Motriz: Revista de Educação Física, v. 16, n. 3, p. 580-590, 2010.

RIBEIRO, L. R. C. Aprendizagem baseada em problemas (PBL): uma experiência no ensino superior. São Carlos: UduFSCAR, 2010.

SAVERY, J. R. Overview of problem-based learning: definitions and distinctions. Interdisciplinary Journal of Problem-based Learning. v. 1, n. 1, p. 9-20, 2006.

SAVERY, J. R.; DUFFY, T. M. Problem-based learning: an instructional model and its constructivist framework. Educational Technology, v. 35, p. 1-17, 1995.

SCHMIDT, H. G. et al. Constructivist, problem-based learning does work: a meta-analysis of curricular comparisons involving a single medical school. Educational Psychologist, v. 44, n. 4, p. 227-249, 2009. https://doi.org/10.1080/00461520903213592

SIQUEIRA, J. R. M. et al. Aprendizagem Baseada em Problemas: O que os Médicos tem a ensinar aos Contadores. Revista Contabilidade Vista e Revista. UFMG. BH, v.20, n.3, p. 101-125, jul./set. 2009.

SOARES, M. A. Aplicação do método de ensino Problem Based Learning (PBL) no curso de Ciências Contábeis: um estudo empírico. 2008. 214 f. Dissertação (Mestrado) Faculdade de Economia, Administração e Contabilidade de Ribeirão Preto, Universidade de São Paulo, Ribeirão Preto, 2008.

SOCKALINGAM, N. Characteristics of problems in problem-based learning. 2010. 236f. Tese (Doutorado em Filosofia) - Erasmus University em Rotterdam, Holanda, 2010.

SOCKALINGAM, N.; MARTINS, D. B.; FREZATTI, F. Practical issues in implementing problem-based learning: an international perspective. In: INTERNATIONAL CONGRESS PAN PBL 2014, 8, Concepción, Chile, 2014. Anais..., 2014.

SOCKALINGAM, N.; SCHMIDT, H. G. Characteristics of problems for problem-based learning: the students' perspective. Interdisciplinary Journal of Problem-based Learning, v. 5, n. 1, p. 6-33, Spring, 2011.

SOUZA, M. K. et al. Termo de consentimento livre e esclarecido (TCLE): fatores que interferem na adesão. Arquivos Brasileiros de Cirurgia Digestiva, v. 26, n. 3, p. 200-205, 2013. 
SOUZA, S. C.; DOURADO, L. Aprendizagem baseada em problemas (ABP): Um método de aprendizagem inovador para o ensino educativo. Holos, v. 5, p. 182-200, 2015.

SPRAAKMAN, G.; JACKLING, B. A conceptual framework for learning management accounting. Accounting Perspectives, v. 13, n. 1, p. 61-81, 2014.

https://doi.org/10.1111/1911-3838.12024

STAKE, R. E. The Case Study Method in Social Inquiry. Educational Researcher, v. 7, n. 2, p. 5-8, 1978.

STANLEY, T.; MARSDEN, S. Problem-based learning: does accounting education need it? Journal of Accounting Education, v. 30, p. 267-289, 2012.

TAILLE, Y. Desenvolvimento do juízo moral. In: MACEDO, L. (Colab.). Jean Piaget. Coleção memória da pedagogia. n. 1. Rio de Janeiro: Ediouro; Segmentto-Duetto, 2005. p. 76-88.

WOOD, D. F. ABC of learning and teaching in medicine: problem-based learning. British Medical Journal (BMJ), v. 326, p. 328-330, 2003.

YIN, R. K. Estudo de caso: planejamento e métodos. 5. ed. Porto Alegre: Bookman, 2015. 